\title{
Potencial antiviral e virucida da melitina e apamina contra herpesvírus bovino tipo 1 e vírus da diarreia viral bovina ${ }^{1}$
}

\author{
Tony Picoli2*, Cristina M. Peter ${ }^{3}$, Gilberto D. Vargas ${ }^{4}$, Silvia O. Hübner ${ }^{4}$, \\ Marcelo de Lima ${ }^{4}$ e Geferson Fischer ${ }^{4}$
}

\begin{abstract}
Picoli T., Peter C.M., Vargas G.D., Hübner S.O., Lima M. \& Fischer G. 2018. [Antiviral and virucidal potential of melittin and apamin against bovine herpesvirus type 1 and bovine viral diarrhea virus.] Potencial antiviral e virucida da melitina e apamina contra herpesvírus bovino tipo 1 e vírus da diarreia viral bovina. Pesquisa Veterinária Brasileira 38(4):595-604. Departamento de Veterinária Preventiva, Universidade Federal de Pelotas, Campus Capão do Leão, Av. Eliseu Maciel s/n, Jardim América, Capão do Leão, RS 96900-010, Brazil. E-mail: picolivet@gmail.com

The search for an alternative to synthetic drugs have revealed discoveries in the field of pharmacology and, according to melittin and apamin, two components of bee venom which have been described were with various pharmacological actions.This study aimed to evaluate the in vitro antiviral and virucidal capabilities of these components. Therefore, after verification of their toxic doses by MTT (3-(4,5-dimethylthiazol-2-yl)-2,5-diphenyltetrazolium bromide) assay, MDBK cells (Madin Darby Bovine Kidney) have been cultivated in microplates and treated with different concentrations of apamin, melittin and its association. This treatment occurred before and after infection with MOI (multiplicity of infection) 0.1 of cytopathogenic strains of bovine herpesvirus type 1 (BoHV-1) strain Los Angeles and bovine viral diarrhea virus (BVDV) strain NADL. After incubation for 72 hours, $37^{\circ} \mathrm{C}$, the cells were submitted to MTT assay to estimate cell viability. In parallel experiments, plates were subjected to the same procedure suffered freezing and thawing cycle the cells to rupture the same and measurement of viral titers. The virucidal assay was performed by incubating suspension of bovine herpesvirus type- 1 and BVDV with apamin solutions, melittin and association for 24 hours at $37^{\circ} \mathrm{C}$ and $22^{\circ} \mathrm{C}$. The viral titer was evaluated at 0 hours, $1,2,4,8$ and 24 hours of incubation. The cytotoxic concentration to $50 \%$ of the cells (CC50) of melittin was $2.32 \mathrm{~g} / \mathrm{mL}$ and apamin did not show toxicity at the greater concentration tested $(100 \mu \mathrm{g} / \mathrm{mL})$. There was antiviral effect of melittin on bovine herpesvirus type- 1 , especially at a concentration of $2 \mu \mathrm{g} / \mathrm{mL}$, where was observed $85.96 \%$ cell viability when treatment was performed before the infection and $86.78 \%$ viability when the treatment was carried out after infection. There was also a $90 \%$ reduction of viral particles of bovine herpesvirus type-1. In lower concentrations ( 1 and $1.5 \mu \mathrm{g} / \mathrm{mL}$ ) melittin no antiviral activity because cell viability was low, showing cytopathic effect of the virus. At the association two substances there were a decrease in the title of BVDV and there was higher cell viability when compared to the isolated action of the compounds of this virus. This is confirmed in the virucidal activity, since there was a decrease of $90 \%$ of the viral particles of BVDV with the combination of the two compounds of bee venom. Acting individually, melittin showed antiviral effect and virucidal against for BoHV-1, zeroing its title in just 2 hours at $37^{\circ} \mathrm{C}$. It is concluded that melittin has antiviral and virucidal action against the BoHV-1 and its association with apamin potentiate its effects against BVDV.
\end{abstract}

INDEX TERMS: Melittin, apamin, bovine herpesvirus type 1, bovine viral diarrhea, virus antimicrobial, cattle, bee venom, BoHV-1, BVDV, viroses.

\footnotetext{
${ }^{1}$ Recebido em 5 de maio de 2016.

Aceito para publicação em 13 de dezembro de 2016.

2 Programa de Pós-graduação em Veterinária, Universidade Federal de Pelotas (UFPel), Campus Capão do Leão, Av. Eliseu Maciel s/n, Capão do Leão, RS 96900-010, Brasil. *Autor para correspondência: picolivet@gmail.com
}

\footnotetext{
${ }^{3}$ Universidade Federal de Pelotas (UFPel), Campus Capão do Leão, Av. Eliseu Maciel s/n, Capão do Leão, RS 96900-010, Brasil.

${ }^{4}$ Departamento de Veterinária Preventiva, Universidade Federal de Pelotas (UFPel), Campus Capão do Leão, Av. Eliseu Maciel s/n, Capão do Leão, RS 96900-010, Brasil.
} 
RESUMO.- A busca por alternativa aos fármacos sintéticos têm revelado descobertas no campo da farmacologia e, nesse sentido, melitina e apamina, dois constituintes do veneno de abelhas, foram descritas com várias ações farmacológicas. Este estudo objetivou avaliar in vitro as capacidades antiviral e virucida destes componentes. Para tanto, células MDBK (Madin Darby Bovine Kidney), após verificação das respectivas doses tóxicas por ensaio MTT ((3-(4,5 dimetiltiazol-2yl)-2-5-difenil-2 $\mathrm{H}$ tetrazolato de bromo), foram cultivadas em microplacas e tratadas com diferentes concentrações de apamina, melitina e sua associação. Esse tratamento ocorreu antes e após a infecção com 0,1 MOI (multiplicidade de infecção) de cepas citopatogênicas de herpesvírus bovino tipo 1 (BoHV-1) cepa Los Angeles e vírus da diarreia viral bovina (BVDV) cepa NADL. Após incubação por 72 horas, $37^{\circ} \mathrm{C}$, as células foram submetidas ao ensaio MTT para estimativa da viabilidade celular. Em experimento paralelo, placas que foram submetidas ao mesmo procedimento sofreram ciclo de congelamento e descongelamento das células, para rompimento das mesmas e mensuração dos títulos virais. $\mathrm{O}$ ensaio virucida foi realizado incubando-se suspensões de BoHV-1 e BVDV com as soluções de apamina, melitina e associação por 24 horas a $37^{\circ} \mathrm{C}$ e $22^{\circ} \mathrm{C}$. $\mathrm{O}$ título viral foi avaliado às 0 horas, 1, 2, 4, 8 e 24 horas de incubação. A concentração citotóxica para $50 \%$ das células $\left(\mathrm{CC}_{50}\right)$ de melitina foi $2,32 \mu \mathrm{g} / \mathrm{ml}$ e apamina não demonstrou toxicidade à maior concentração testada $(100 \mu \mathrm{g} / \mathrm{ml})$. Houve efeito antiviral da melitina sobre BoHV-1, especialmente na concentração de $2 \mu \mathrm{g} / \mathrm{ml}$, onde observou-se $85,96 \%$ de viabilidade celular quando o tratamento foi realizado antes da infecção e $86,78 \%$ de viabilidade quando o tratamento foi realizado após a infecção. Houve ainda redução de $90 \%$ das partículas virais de BoHV-1.

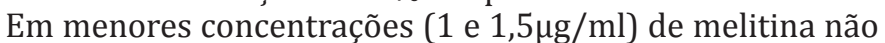
houve atividade antiviral, pois a viabilidade celular foi baixa, demonstrando efeito citopático do vírus. Na associação das duas substâncias houve queda no título de BVDV e observou-se maior viabilidade celular quando comparados à ação isolada dos composto sobre este vírus. Isso se confirma na atividade virucida, uma vez que houve decréscimo de $90 \%$ das partículas virais de BVDV com a associação dos dois compostos do veneno de abelhas. Atuando individualmente, melitina apresentou efeito antiviral e virucida frente ao BoHV-1, zerando seu título em apenas 2 horas a $37^{\circ} \mathrm{C}$. Conclui-se que melitina tem ação antiviral e virucida frente ao BoHV-1 e sua associação com apamina potencializou seus efeitos frente ao BVDV.

TERMOS DE INDEXAÇÃO: Melitina, apamina, herpesvírus bovino tipo 1 , vírus da diarreia viral bovina, bovinos, antimicrobiano, veneno de abelha, BoHV-1, BVDV, viroses.

\section{INTRODUÇÃO}

A busca por novos agentes farmacologicamente ativos tem levado à descoberta de diversos compostos naturais com propriedades antimicrobianas (Cragg et al. 1997). Os peptídeos antimicrobianos naturais são essenciais na defesa de diversos organismos, microscópicos ou não. Até os dias atuais, mais de 750 compostos proteicos com esta característica foram identificados em bactérias, fungos, vírus, plantas, insetos, moluscos, crustáceos, aracnídeos, aves, anfíbios, peixes e mamíferos (Cuthbertson et al. 2002, Silva Junior et al. 2002, Zasloff 2002, Brogden et al. 2003). Peptídeos sintéticos podem ser criados para atuar sobre uma diversidade de patógenos simulando ou interagindo com proteínas de superfície conservadas, a fim de preservar a eficácia terapêutica. Nos últimos anos, pesquisadores têm explorado diversos métodos para melhorar a tecnologia de síntese e ação desses peptídeos (Fosgerau \& Hoffmann 2015). Os mecanismos de ação antiviral de peptídeos incluem principalmente a inibição da penetração viral na célula, destruição do envelope viral e inibição da replicação viral (Skalickova et al. 2015).

A comunidade científica enfrenta novos desafios com relação à vigilância, tratamento e prevenção de viroses emergentes como é o caso das infecções pelos vírus zika, chikungunya e dengue, que vêm causando alerta, principalmente nas Américas (Heukelbach et al. 2016, Kantor 2016, Brasil 2015). Essas dentre outras viroses levam à busca por novos antivirais, que por sua vez têm levado à descoberta ou à síntese de compostos que causam euforia momentânea no panorama de enfermidades de difícil tratamento, porém, às vezes, é rapidamente frustrada frente ao rápido aparecimento de cepas resistentes aos novos fármacos, como foi o caso da síndrome da imunodeficiência adquirida (AIDS), das infecções pelas várias faces do vírus Influenza, assim como diversas outras viroses (De Clercq 2001). De maneira semelhante, permanece insuficiente a disponibilidade dos fármacos antivirais oriundos de produtos naturais, devido à utilidade terapêutica limitada e o grau de toxicidade (Strohl 2000, Faulkner 2002). A busca por um fármaco antiviral estável e de baixa toxicidade deve ser aliada à capacidade de controlar enfermidades que cursem com alta mortalidade ou morbidade. É o caso da rinotraqueíte infecciosa bovina e da diarreia viral bovina, duas enfermidades víricas de importância médico-veterinária, responsáveis por alta morbidade e por vultosos prejuízos financeiros aos produtores rurais, causadas, respectivamente, pelo herpesvírus bovino tipo 1 (BoHV-1) e pelo vírus da diarreia viral bovina (BVDV) (Flores 2012).

A melitina é um conhecido peptídeo tóxico, anfipático, em hélice com carga positiva localizada em sua porção carboxi-terminal (Bello et al. 1982, Glättli et al. 2006), presente no veneno de abelhas melíferas, compreendendo aproximadamente 50\% do seu peso seco (Habermann 1972, Cruz-Landim \& Abdalla 2002). Com apenas 26 aminoácidos em sua conformação, é a toxina mais ativa do veneno. Quando armazenada na vesícula de veneno, arranja-se de forma tetramérica diminuindo sua toxicidade (Cardoso et al. 2003). Entretanto, quando o veneno é liberado, dissocia-se e, individualmente, sua forma monomérica passa a ter alta toxicidade e, quando associada à fosfolipase $\mathrm{A} 2$, também presente no veneno, tem sua ação amplificada e ainda modula a ação das fosfolipases, aumentando suas ações catalíticas (Cardoso et al. 2003, Koumanov et al. 2003). Possui rápida ação citolítica, desestabilizando membranas celulares e liberando conteúdo citoplasmático de diversos tipos celulares (Dempsey 1990). Esta capacidade lítica não se restringe às células animais, uma vez que apresenta capacidades antibacteriana e antifúngica conhecidas (Asthana et al. 2004).

Outro peptídeo bioativo presente na composição do veneno de abelha é a apamina, que corresponde a cerca de $2 \%$ do peso seco. É a menor neurotoxina conhecida, com apenas 18 aminoácidos, e age nas membranas pós-sinápticas do sistema nervoso central e periférico, bloqueando a transmissão 
de determinados impulsos inibitórios (Cruz-Landim \& Abdalla 2002, Cardoso et al. 2003).

Devido à escassez de informações, este estudo objetivou contribuir com as pesquisas em busca de novos compostos antimicrobianos avaliando o potencial antiviral e/ou virucida da melitina e da apamina frente aos vírus de importância em medicina veterinária, BoHV-1 e BVDV.

\section{MATERIAL E MÉTODOS}

Material. Melitina e apamina, adquiridos comercialmente (Sigma-Aldrich Corp., St. Louis, MO) com pureza de 85\% e 99\%, respectivamente, foram dissolvidas em tampão salina-fosfato (PBS) estéril pH 7,2 até concentração de $1 \mathrm{mg} / \mathrm{ml}$ e estocadas em temperatura inferior a $-70^{\circ} \mathrm{C}$ até o momento do uso. Para ensaios de citotoxicidade, melitina e apamina foram diluídas em Meio Essencial Mínimo (E-MEM, Sigma-Aldrich Corp., St. Louis, MO) atingindo concentrações que variaram de 1 a $10 \mu \mathrm{g} / \mathrm{ml}$ para melitina, e de 10 a $100 \mu \mathrm{g} / \mathrm{ml}$ para apamina. As associações foram elaboradas utilizando doses de melitina e apamina na proporção em que se encontram na apitoxina

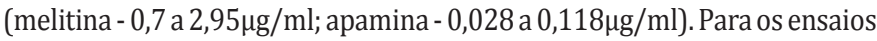
da atividade antiviral, os compostos foram diluídos sem E-MEM até alcançar

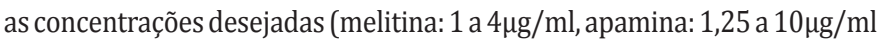
e sua associação foi utilizada nas proporções em que se encontram no veneno natural, variando de 1 a $4 \mu \mathrm{g} / \mathrm{ml}$ de melitina e 0,04 a $0,16 \mu \mathrm{g} / \mathrm{ml}$ de apamina).

Células da linhagem MDBK (Madin Darby Bovine Kidney) foram selecionadas por ser permissíveis aos vírus estudados. Essas células foram cultivadas em E-MEM acrescido de $10 \%$ de soro fetal bovino (SFB, Gibco, Grand Island, NY) e antibióticos penicilina (Sigma-Aldrich ${ }^{\circledR}$, USA), estreptomicina (Vetec ${ }^{\circledast}$, Brasil), enrofloxacina (Bayer ${ }^{\circledast,}$ Brasil) e anfotericina B (Cristália ${ }^{\circledR}$, Brasil) em placas de poliestireno de 96 cavidades (Kasvi ${ }^{\oplus}$, Brasil) em temperatura de $37^{\circ} \mathrm{C}$ em ambiente com $5 \%$ de $\mathrm{CO}_{2}$, até o estabelecimento de monocamada em concentração de $1 \times 10^{7}$ células $/ \mathrm{ml}$.

Os experimentos foram realizados frente à cepas citopatogênicas de BoHV-1, cepa Los Angeles e BVDV, cepa NADL pertencentes ao Laboratório de Virologia e Imunologia Animal, UFPel. Em ambos os casos, quando da necessidade de inoculação, utilizou-se 0,1 MOI.

Ensaios de citotoxicidade. Células MDBK previamente cultivadas em placas de 96 cavidades por 24 horas foram tratadas com as concentrações de melitina, apamina e sua associação $(100 \mu \mathrm{l} /$ poço). Os testes foram realizados em sextuplicata e incubados por 72 horas, sob as mesmas condiç̃os até o momento da leitura. Como controles foram utilizadas células mantidas em E-MEM suplementado, sem nenhum tipo de tratamento. Após essas etapas, as placas foram submetidas ao ensaio com o reagente MTT (3-(4,5 dimetiltiazol-2yl)-2-5-difenil-2H tetrazolato de bromo) segundo Mosmann (1983). Os percentuais de viabilidade celular (CV) foram calculados segundo a fórmula: $\mathrm{CV}=\mathrm{AT} / \mathrm{ACx} 100$, onde AT e AC significam a absorbância das células tratadas e do controle de células, respectivamente e, dessa forma foram obtidas a concentração inibitória para 50\% do cultivo celular (CI50\%) e para 90\% do cultivo celular (CI90\%).

Ensaios da atividade antiviral. Os títulos virais estão expressos como doses infectantes para $50 \%$ de cultivos celulares $\left(\mathrm{CCID}_{50}\right) \mathrm{e}$ a atividade antiviral foi expressa em percentual de inibição (PI) e calculada através dos títulos virais pela fórmula:

$$
\left[1-\left(\frac{\text { antilog tratamento }}{\text { antilog controle }}\right)\right] \times 100
$$

A atividade antiviral foi avaliada através de dois métodos distintos: através da viabilidade celular e do título viral. Cada um dos dois métodos ainda foi testado quanto ao momento da infecção: a) tratamento das células com melitina, apamina ou sua associação antes da infecção, eb) tratamento das células após a infecção. Todas as análises foram realizadas em sextuplicata: (a) Tratamento antes da

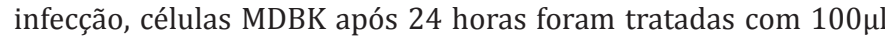
de cada um dos tratamentos e após 24 horas, o sobrenadante foi removido e sobre as células foi adicionado o vírus (BoHV-1 ou BVDV). Após 72 horas de incubação, a leitura se deu por duas formas distintas: através da viabilidade celular pelo teste MTT e através do título viral através do método de Reed \& Muench (1938). As placas destinadas à realização da titulação viral foram congeladas e descongeladas para rompimento de células; (b) Tratamento após infecção: após crescimento em placas, as células foram infectadas com os vírus por duas horas, quando foi removido, e os tratamentos realizados sobre as células. Após 72 horas foi realizada a leitura da mesma maneira descrita.

Ensaio da atividade virucida. BoHV-1 e BVDV foram incubados com melitina $(25 \mu \mathrm{g} / \mathrm{ml})$, apamina $(100 \mu \mathrm{g} / \mathrm{ml})$ e sua associação (melitina $25 \mu \mathrm{g} / \mathrm{ml}+$ apamina $100 \mathrm{ng} / \mathrm{ml}$ ) por até 24 horas sob temperaturas de $22^{\circ} \mathrm{C}$ e $37^{\circ} \mathrm{C}$. As concentrações selecionadas dos compostos foram baseadas nos resultados dos testes de citotoxicidade. Durante a incubação, em seis momentos (zero, uma, duas, quatro, oito e vinte e quatro horas), foram coletadas alíquotas das suspensões víricas com os tratamentos para realização das titulações virais.

Análise estatística. Foi realizada análise de variância com comparação entre médias pelo teste de Tukey adotando uma significância de $95 \%$ como base para afirmar diferenças entre médias. As análises foram realizadas com auxílio do software estatístico BioEstat ${ }^{\circledR}$ versão 5.3.

\section{RESULTADOS}

$\mathrm{A} \mathrm{CC}_{50}$ de melitina para células MDBK foi de $2,32 \mu \mathrm{g} / \mathrm{ml}$ e a CC $\mathrm{CO}_{90}$ foi de $2,76 \mu \mathrm{g} / \mathrm{ml}$. Para apamina, não foi possível estabelecer uma $\mathrm{CC}_{50}$ ou $\mathrm{CC}_{90}$, pois as maiores concentrações testadas atingiram apenas $12,58 \pm 0,53 \%(p>0.05, n=6)$ de destruição celular.

Quanto aos ensaios antivirais, observa-se na Fig. 1 o efeito de melitina sobre o BoHV-1, especialmente na concentração de $2 \mu \mathrm{g} / \mathrm{ml}$, em ambas avaliações (tratamento pré e pós infecção). Nesta concentração de melitina, houve destruição em apenas $14,04 \% \pm 3,86 \%(n=6, p<0,01)$ das células com tratamento antes da infecção e apenas 13,22\% $\pm 4,41 \%(n=6, p<0,01)$ com tratamento pós-infecção, se aproximando ao controle de células, que não foi submetido a tratamento ou infecção. As menores concentrações de melitina $(0,5 \mu \mathrm{g} / \mathrm{ml}$ e $1 \mu \mathrm{g} / \mathrm{ml})$ não apresentaram efeito antiviral, uma vez que houve destruição de mais de $50 \%$ das células sugerindo que houve ação viral. As maiores concentrações ( $3 \mu \mathrm{g} / \mathrm{ml} \mathrm{e} 4 \mu \mathrm{g} / \mathrm{ml}$ ) apresentaram destruição celular, provavelmente causada pela toxicidade da própria melitina. Em ambos os tratamentos, a concentração de $2 \mu \mathrm{g} / \mathrm{ml}$ reduziu o título de BoHV-1 de 6,25 $\mathrm{CCID}_{50} / 25 \mu \mathrm{l}$ para $5,25 \mathrm{CCID}_{50} / 25 \mu \mathrm{l}$, indicando PI=90\%. Com o tratamento pré-infecção na maior concentração testada, o título de BoHV-1 caiu para $4,75 \mathrm{CCID}_{50} / 25 \mu \mathrm{l}(\mathrm{PI}=96,8 \%)$ e tratamento pós-infecção o título caiu para $4,25 \mathrm{CCID}_{50} / 25 \mu \mathrm{l}(\mathrm{PI}=99 \%)$.

Quanto à atividade de melitina sobre o BVDV, nas concentrações testadas, a porcentagem de células viáveis variou de $21,69 \% \pm 0,77 \%$ a $31 \% \pm 1,27 \%$ (n=6, $<<0,01)$ no tratamento pré-infecção, e de $21,29 \% \pm 0,84 \%$ a $31,42 \% \pm 1,2 \%(n=6, p<0,01)$ 

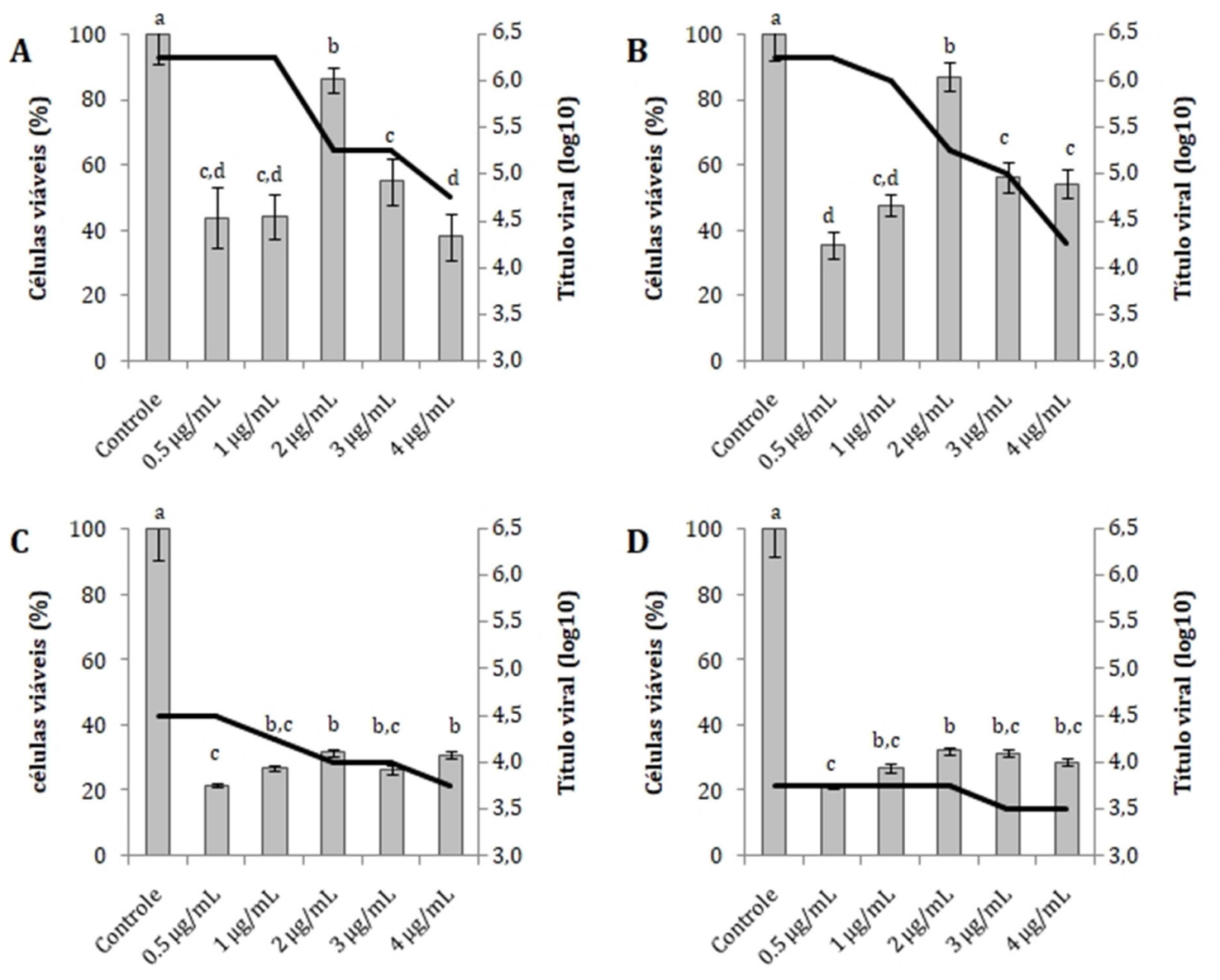

\% células viáveis

- Título viral

Fig.1. Atividade antiviral da melitina após 72 horas. (A) Tratamento pré-infecção frente ao herpervírus bovino tipo 1 (BoHV-1).

(B) Tratamento pós-infecção frente ao BoHV-1. (C) Tratamento pré-infecção frente ao vírus da diarreia viral bovina (BVDV).

(D) tratamento pós-infecção frente ao BVDV. Letras diferentes entre as colunas indicam diferença estatística pelo teste de Tukey $(\mathrm{p}<0,05)$.

no tratamento pós-infecção, indicando que em todos os tratamentos houve efeito citopático causado pelo vírus. Estes dados são confirmados pelo título viral que não apresentou queda marcante em nenhuma das concentrações de melitina testadas. Sendo assim, frente ao BVDV, melitina não apresentou efeito antiviral nas doses testadas.

Apamina, nas doses testadas, não apresentou atividade antiviral frente ao BoHV-1 ou BVDV, havendo queda no título de BoHV-1, de 6,25 para 5,75 $\mathrm{CCID}_{50} / 25 \mu \mathrm{l}, \mathrm{PI}=68,38 \%$ tanto no tratamento pré-infecção como no pós-infecção. No caso de BVDV, o título caiu de 4,25 para 3,75 $\mathrm{CCID}_{50} / 25 \mu \mathrm{l}$, $\mathrm{PI}=68,38 \%$ com o tratamento pré-infecção e no tratamento pós-infecção, o título caiu de 4,25 para 4 CCID $_{50} / 25 \mu$ l em todas as concentrações testadas (PI=43,77\%). Em todos os ensaios antivirais com apamina, a viabilidade celular não passou de $49 \%$ frente ao BoHV-1 e de $24 \%$ frente ao BVDV e, como não foi encontrada dose tóxica de apamina para células MDBK, a baixa viabilidade celular demonstra efeito citopático viral.

A associação de melitina e apamina amplificou a resposta frente aos vírus testados (Fig. 2). Na maior concentração testada, o título de BoHV-1 caiu de 6,3 para $4,25 \mathrm{CCID}_{50} / 25 \mu \mathrm{l}$, PI=99,2\% em ambos tratamentos (antes e após infecção). No tratamento apenas com melitina, a redução do título foi de 6,3 para 4,75 $\mathrm{CCID}_{50} / 25 \mu \mathrm{l}(\mathrm{PI}=97,18 \%)$. Com o tratamento pré-infecção, na associação C $(2 \mu \mathrm{g} / \mathrm{ml}$ de melitina $+0,08 \mu \mathrm{g} / \mathrm{ml}$ de apamina), houve maior viabilidade celular $(80,9 \% \pm 1,57 \%)$ e o título de BoHV-1 caiu 86,82\% em relação ao controle. Com o tratamento pós-infecção, na mesma associação $\mathrm{C}$, houve $79,8 \% \pm 3,09 \%$ de viabilidade celular e $\mathrm{PI}=95,53 \%$. Na associação D, o título de BoHV- 1 caiu para $4,6 \mathrm{CCID}_{50} / 25 \mu \mathrm{l}$, indicando $\mathrm{PI}=98 \%$, demonstrando também, atividade antiviral.

Os resultados mais expressivos que demonstram o aumento da atividade dos compostos quando atuam em associação, estão vinculados aos ensaios frente ao BVDV que, no tratamento pré-infecção, apresentou queda de $1,5 \log _{10}$ do título viral (PI=96,84\%) na maior concentração testada. Na concentração C, onde se obteve a maior viabilidade celular $(53,45 \% \pm 3,13 \%)$, o título caiu $0,64 \log _{10}$ (PI=77,09\%), ao passo que, no tratamento apenas com melitina na mesma concentração, a redução do título viral foi de $0,5 \log _{10}$ e a viabilidade celular não passou dos $31,73 \% \pm 1,09 \%$. Vale ressaltar que o uso apenas de apamina não resultou em atividade antiviral. 0 tratamento pós-infecção com a associação demonstrou resultados semelhantes, potencializando o efeito das substâncias frente aos vírus testados. 

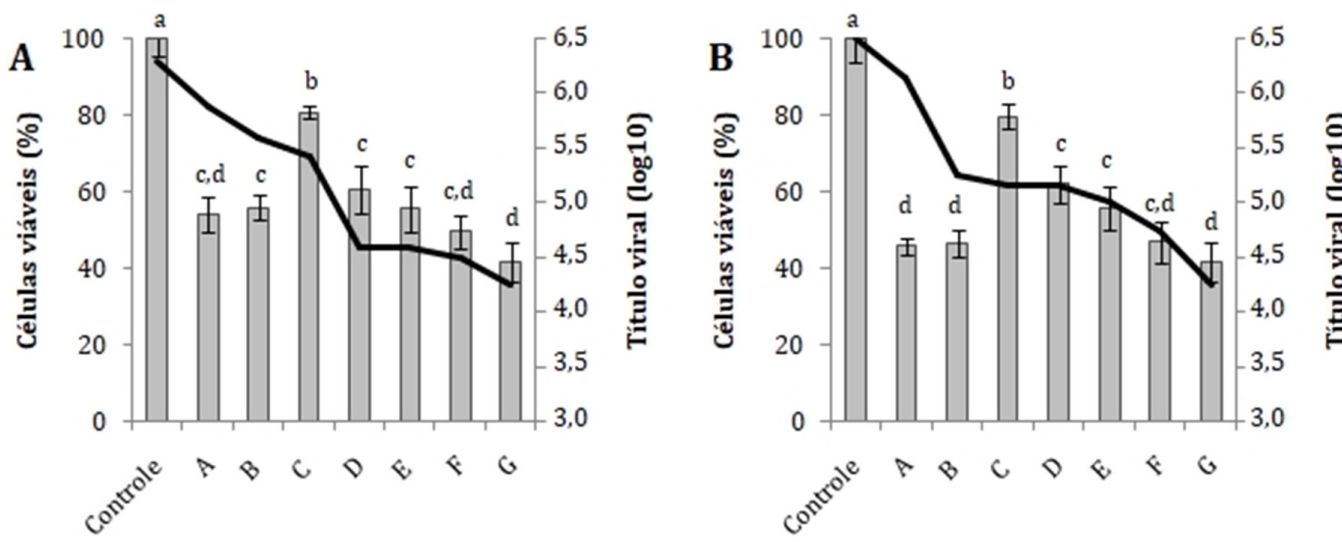

Tratamentos (melitina + apamina)

Tratamentos (Melitina + apamina)

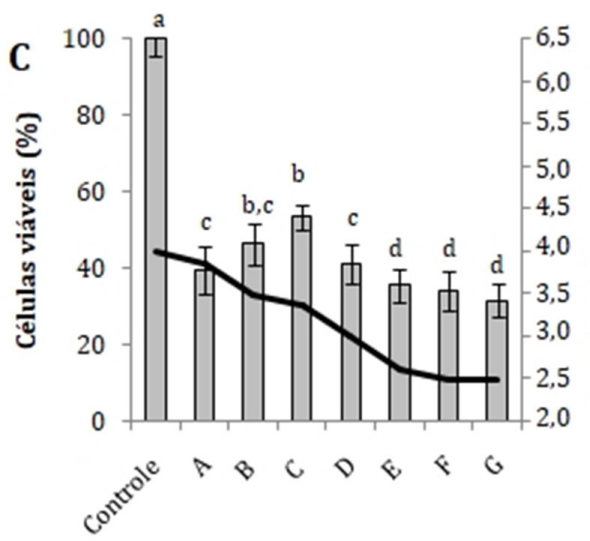

Tratamentos (melitina + apamina)

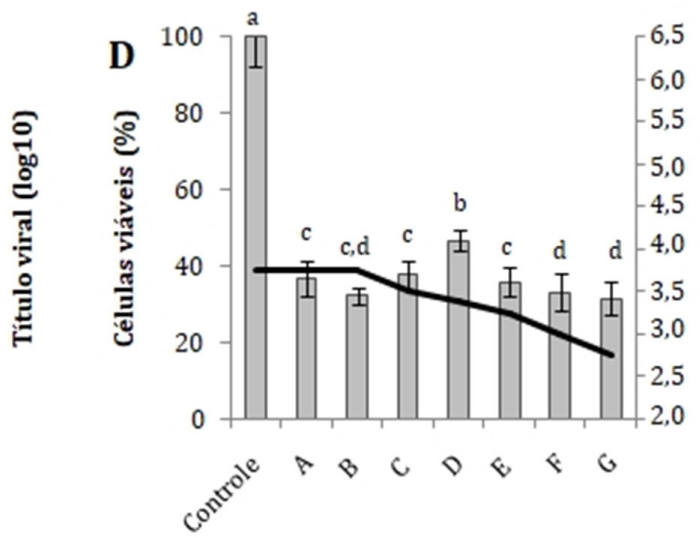

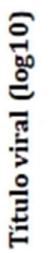

\% células viáveis

Tratamentos (melitina + apamina)

Fig.2. Atividade antiviral da associação entre melitina e apamina após 72 horas. (A) Tratamento pré-infecção frente ao herpervírus bovino tipo 1 (BoHV-1). (B) Tratamento pós-infecção frente ao BoHV-1. (C) Tratamento pré-infecção frente ao vírus da diarreia

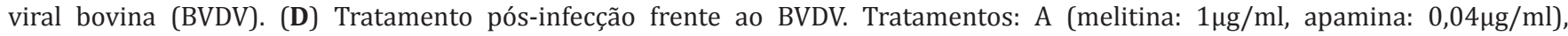

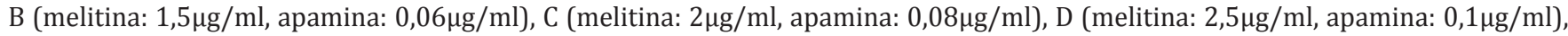

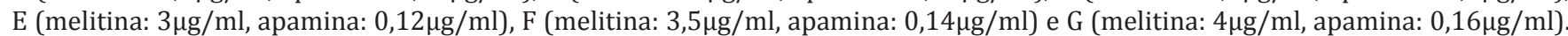
Letras diferentes entre as colunas indicam diferença estatística pelo teste de Tukey $(\mathrm{p}<0,05)$.
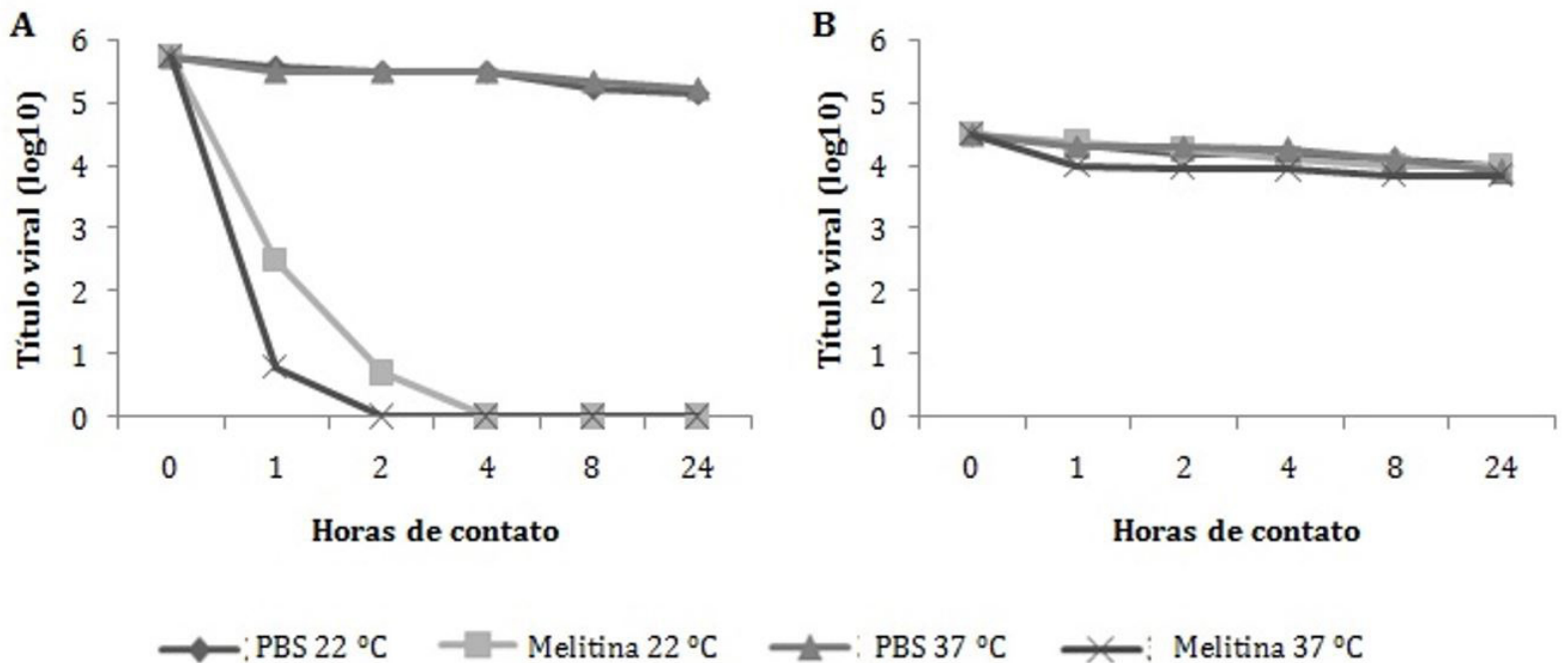

Fig.3. Atividade virucida de melitina $(25 \mu \mathrm{g} / \mathrm{ml})$ após 24 horas de contato com os vírus. (A) Título de BoHV-1. (B) Título de BVDV, contato com PBS a $22^{\circ} \mathrm{C}(\diamond)$, contato com PBS a $37^{\circ} \mathrm{C}(\boldsymbol{\Delta})$, contato com melitina a $22^{\circ} \mathrm{C}(\boldsymbol{\bullet})$, contato com melitina a $37^{\circ} \mathrm{C}(\times)$. 

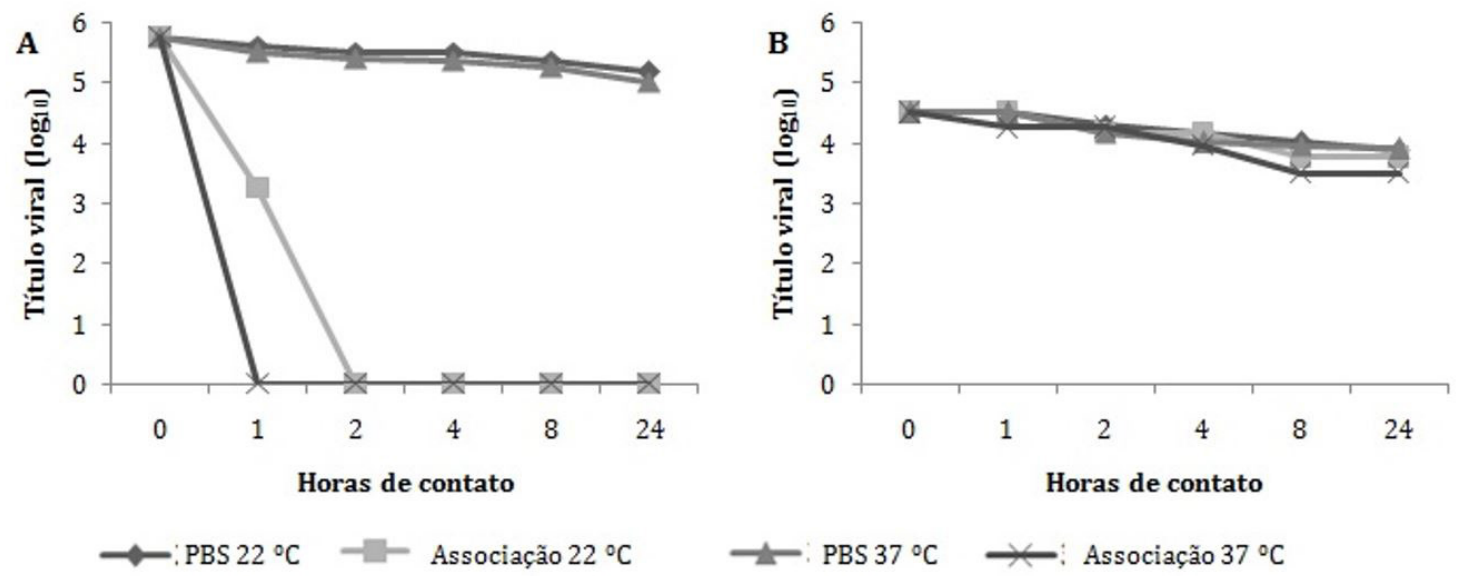

Fig.4. Atividade virucida da associação entre melitina $(25 \mu \mathrm{g} / \mathrm{ml})$ e apamina $(100 \mathrm{ng} / \mathrm{ml})$ após 24 horas de contato com os vírus. (A) Título de BoHV-1. (B) Título de BVDV, contato com PBS a $22^{\circ} \mathrm{C}(\diamond)$,contato com PBS a $37^{\circ} \mathrm{C}(\boldsymbol{\Delta})$, contato com associação a $22^{\circ} \mathrm{C}(\boldsymbol{\square})$, contato com associação a $37^{\circ} \mathrm{C}(\times)$.

Quanto à atividade virucida de melitina, a Figura 3 ilustra os resultados obtidos a partir da avaliação do título viral em períodos pré-estabelecidos de contato com melitina, sob duas temperaturas. Houve efeito virucida sobre BoHV-1, que foi totalmente inativado em apenas duas horas de incubação com melitina a $25 \mu \mathrm{g} / \mathrm{ml}$ sob temperatura de $37^{\circ} \mathrm{C}$ e em quatro horas sob $22^{\circ} \mathrm{C}$. Os títulos controle (vírus incubado com PBS, sob ambas temperaturas) variaram de $5,75 \mathrm{CCID}_{50} / 25 \mu \mathrm{l}$ a $5,16 \mathrm{CCID}_{50} / 25 \mu \mathrm{l}$ em 24 horas. Melitina, na concentração testada, não apresentou efeito sobre BVDV.

A associação de melitina com apamina (Fig.4) apresentou efeito virucida frente ao BoHV-1 seguindo o mesmo padrão da melitina atuando individualmente, porém a $37^{\circ} \mathrm{C}$ o título foi zerado em apenas uma hora de incubação. A associação ainda potencializou a ação contra o BVDV. Sob temperatura de $37^{\circ} \mathrm{C}$ após 24 horas de incubação, a associação permitiu redução do título de BVDV de 4,5 para $3,5 \mathrm{CCID}_{50} / 25 \mu \mathrm{l}$, o que significa uma queda de $90 \%$ no número de partículas virais. No mesmo período, o controle demonstrou $\mathrm{PI}=74,88 \%$.

Apamina individualmente não apresentou efeitos contra o BVDV. Porém a associação entre as duas substâncias potencializou o efeito sobre este vírus. Nas concentrações testadas, não houve efeito de apamina sobre BoHV-1 ou BVDV.

\section{DISCUSSÃO}

Os dados obtidos com os testes de citotoxicidade corroboram com Zhou et al. (2013) que também relatam a ação dose-dependente da melitina em células HepG2. Quanto à apamina, na dose de $800 \mu \mathrm{g} / \mathrm{ml}$, esses autores encontraram apenas $34,98 \pm 1,37 \%$ ( $p>0,05, n=6$ ) de morte celular, não sendo possível, portanto, o estabelecimento da CC 50\%, assim como em nosso estudo. Dessa forma, para as análises da atividade antiviral, foram escolhidas concentrações específicas de trabalho.

Os dois ensaios com BoHV-1 revelaram efeito antiviral na concentração $2 \mu \mathrm{g} / \mathrm{ml}$ de melitina. Esses resultados concordam com nosso estudo citotóxico, onde a CC50 da melitina ficou em $2,32 \mu \mathrm{g} / \mathrm{ml}$ e a CC90, em $2,76 \mu \mathrm{g} / \mathrm{ml}$. A concentração de $2 \mu \mathrm{g} / \mathrm{ml}$, por não ser tóxica para as células, demonstra a real influência sobre o vírus e, após infecção e incubação por 72 horas, a quantidade de células viáveis foi superior às demais concentrações, aproximando-se ao controle de células, provando o efeito antiviral contra BoHV-1.

0 espectro de vírus que são susceptíveis aos peptídeos catiônicos compreendem basicamente os vírus RNA e RNA envelopados (Jenssen et al. 2006) com algumas exceções como os adenovírus não envelopados (Bastian \& Schäfer 2001, Horne et al. 2005), calicivírus felino (McCann et al. 2003) e echovírus (Pietrantoni et al. 2006). Os mecanismos de ação desses peptídeos sobre vírus normalmente se enquadram nos processos de adsorção ou entrada viral na célula (Belaid et al. 2002) ou como resultado de um efeito direto no envelope viral (Aboudy et al. 1994, Robinson Junior et al. 1998).

Assim como a melitina, outros peptídeos com atividades antimicrobianas também são anfipáticos com cargas positivas e vários grupos de pesquisa têm procurado estabelecer uma ligação entre essas características e a atividade antiviral (Daher et al. 1986, Tamamura et al. 1994, Yasin et al. 2000, Jenssen et al. 2004b). Giansanti et al. (2005) ao realizarem estudos buscando atividade antiviral de peptídeos derivados da ovotransferrina concluíram que a presença de resíduos hidrofóbicos com carga positiva são importantes mas não o suficiente para determinar a atividade antiviral. Essa atividade pode estar relacionada com diferentes conformações adotadas pelos peptídeos. Yasin et al. (2004) demonstraram a importância da carga e da conformação espacial dos peptídeos ao estudar a proteção celular causada por peptídeos ao inibir a adesão viral de herpes simplex vírus. De maneira semelhante, estudos confirmaram a importância de pontes dissulfeto na atividade antiviral de peptídeos com beta-estrutura (Tamamura et al. 1994, Andersen et al. 2001, Jenssen et al. 2004a).

O bloqueio da entrada viral na célula é um dos mecanismos que peptídeos antimicrobianos podem atuar (Jenssen et al. 2006). 0 sulfato de heparan é a molécula de superfície celular mais importante na adesão viral à célula hospedeira (Spillmann 2001, Mettenleiter 2002) e, bloqueando essa molécula, consequentemente a infecção viral é reduzida (Wudunn \& Spear 1989, Shieh et al. 1992). Isso foi demonstrado quando células recombinantes que não expressavam o sulfato de heparan demonstraram $80 \%$ de redução na infecção por herpes simplex virus (Mardberg et al. 2002). A remoção enzimática do sulfato de heparan celular também reduziu as infecções por HIV em 
suas células hospedeiras (Argyris et al. 2003). O bloqueio da entrada viral à célula também pode ocorrer pela interação do peptídeo com receptores virais específicos na superfície da célula hospedeira, influenciando assim a infectividade e a entrada viral (Tamamura et al. 1996). A atividade antiviral de alguns peptídeos também está relacionada à habilidade de impedir a disseminação viral de uma célula à outra (Jenssen et al. 2006).

Uma vez que os vírus foram capazes de se internalizar na célula, alguns peptídeos têm a capacidade de interagir em alvos intracelulares bloqueando a expressão de genes virais (Wachinger et al. 1998) ou na estimulação de genes e proteínas celulares específicas ao combate da infecção viral (Bowdish et al. 2004). De acordo com essa capacidade de interagir com DNA (Hsu et al. 2005, Song et al. 2005), uma das hipóteses aceitas é a influência direta na síntese de ácidos nucléicos virais, como demonstrado pelos peptídeos polyphemusin T22 e lactoferrin. Alguns peptídeos ainda são capazes de desencadear uma atividade imunomodulatória através de citocinas e interferons (Scott et al. 2002, Bowdish et al. 2005, Chang et al. 2005) que cursam com atividade antiviral. Wachinger et al. (1998) relatou a capacidade de melitina em inibir a produção associada às células infectadas pelo HIV-1 suprimindo a expressão de genes deste vírus.

0 rompimento de envelopes virais induzidos por peptídeos ainda é pouco compreendido. Lu et al. (2013) estudaram o comportamento dinâmico de bicamadas lipídicas quando interagem com melitina e os resultados demonstraram que após as interações com a membrana, há a liberação de lipídeos e o rompimento da curvatura natural da bicamada leva a uma micelização dos lipídeos liberados e, assim, o vírus pode ser destruído por aberturas no envelope que permitem a passagem de moléculas de baixo peso molecular.

Sabidamente, melitina atua sobre membranas lipídicas, apresentando uma variedade de efeitos como permeabilização, formação de poros artificiais, rompimento e lise (Ladokhin \& White 2001, Raghuraman \& Chattopadhyay 2007, Lee et al. 2008, Zhang et al. 2011) e, dessa maneira, pode apresentar efeito sobre envelopes virais. Duas hipóteses são mais aceitas para explicar esses mecanismos: os mecanismos denominados "modelo barril" e "modelo carpete". 0 "modelo barril" cursa com rupturas em forma de poros toroidais (em forma de barril) formados pela agregação de melitina perpendicular à superfície da membrana e, a destruição ou permeabilização da bicamada lipídica pelo mecanismo denominada "modelo carpete", ocorre quando uma grande quantidade do peptídeo se distribui paralelamente na superfície da membrana interagindo eletrostaticamente com as cabeças dos lipídeos, desorganizando a bicamada lipídica de modo semelhante a um detergente com consequente permeabilização da mesma (Benachir \& Lafleur 1995, Oren \& Shai 1998, Bechinger 1999, Gordon-Grossman et al. 2012, Gordon-Grossman et al. 2009).

Em nosso estudo, os efeitos dos peptídeos melitina e apamina, atuando individualmente sobre o BVDV não são marcantes, porém há relatos de descrição de peptídeos com efeito sobre vírus RNA. Hood et al. (2013) demonstraram ação de nanopartículas de melitina sobre o vírus da imunodeficiência humana (HIV), sugerindo uma ação sobre o envelope viral. Segundo esses autores, a melitina nas nanopartículas se funde com o envelope viral formando pequenos complexos de poros, inativando o vírus. Ainda elucidam que, ao entrar em contato com células sadias, as nanopartículas não liberam a melitina. Wachinger et al. (1998) também encontraram ação de melitina livre sobre o HIV, porém com estudos moleculares, detectaram a inibição na síntese de RNA mensageiro. Devido à ação de peptídeos, o vírus Influenza também pode ser inativado por esse mecanismo, assim como pelo rompimento de envelope conforme descrito por Skalickova et al. (2015). RNA-polimerase dependente de RNA viral (RdRp), uma enzima limitante na transcrição e replicação do vírus influenza é composta por três subunidades (PB1, PB2 e PA). A subunidade PB1 é responsável pela polimerização e clivagem de endonuclease (Ruigrok et al. 2010, Engler et al. 2011), enquanto PB2 é responsável por reconhecer e se ligar ao mRNA (Fechter et al. 2003, Ma et al. 2011) e, a subunidade PA foi recentemente descrita como responsável pela clivagem do pré-mRNA (Dias et al. 2009, Yuan et al. 2009). 0 complexo RdRp é mantido por meio de ligações não-covalentes e qualquer desestabilização pode ocasionar falha na replicação viral. Li et al. (2011) demonstraram esse mecanismo de ação ao avaliarem a ação de peptídeos frente ao vírus H5N1.

Quando atuam em conjunto, melitina e apamina potencializam os efeitos virucidas, especialmente contra o BVDV e, embora os efeitos dessa associação não tenham sido completamente elucidados, essa potencialização ocorre assim como na associação entre melitina e fosfolipase A2, outro componente enzimático da apitoxina que tem seu efeito regulado e potencializado quando em contato com melitina (Mollay et al. 1976, Saini et al. 1997).

A saúde pública é um tema que exige bastante preocupação nas pesquisas atuais, uma vez que, além da resistência microbiana aos fármacos, existe um apelo por parte da população que vêm exigindo tratamentos menos agressivos ao organismo e, por se tratarem de peptídeos de origem natural, melitina e apamina atendem a essa demanda que é crescente e a cada dia mais fiscalizada. Vírus e outros micro-organismos de interesse em medicina veterinária e humana podem estar sujeitos à sensibilidade frente aos compostos estudados, representando uma ampla linha de pesquisa e potencial à formulação de novos fármacos eficazes.

\section{CONCLUSÕES}

Melitina possui efeito antiviral e virucida sobre BoHV-1 e BVDV, além de apresentar alta citotoxicidade em células MDBK.

Apamina, atuando individualmente, não demonstrou atividade nas concentrações estudadas e frente aos vírus analisados.

O potencial da apamina é demonstrado quando esta é associada à melitina e testadas frente ao BVDV. A associação demonstrou efeito sobre este vírus, tanto na análise antiviral, quanto na virucida.

\section{REFERÊNCIAS}

Aboudy Y., Mendelson E., Shalit I., Bessalle R. \& Fridkin M. 1994. Activity of two synthetic amphiphilic peptides and magainin-2 against herpes simplex virus types 1 and 2. Int. J. Pept. Protein Res. 43(6):573-582. http://dx.doi. org/10.1111/j.1399-3011.1994.tb00559.x. PMid:7928088.

Andersen J.H., Osbakk S.A., Vorland L.H., Traavik T. \& Gutteberg T.J. 2001 Lactoferrin and cyclic lactoferricin inhibit the entry of human cytomegalovirus into human fibroblasts. Antiviral Res. 51(2):141-149. http://dx.doi. org/10.1016/S0166-3542(01)00146-2. PMid:11431038. 
Argyris E.G., Acheampong E., Nunnari G., Mukhtar M., Williams K.J. \& Pomerantz R.J. 2003. Human immunodeficiency virus type 1 enters primary human brain microvascular endothelial cells by a mechanism involving cell surface proteoglycans independent of lipid rafts. J. Virol. 77(22):12140-12151. http://dx.doi.org/10.1128/JVI.77.22.12140-12151.2003. PMid:14581551.

Asthana N., Yadav S.P. \& Ghosh J.K. 2004. Dissection of antibacterial and toxic activity of melittin: a leucine zipper motif plays a crucial role in determining its hemolytic activity bus not antibacterial activity. J. Biol. Chem. 279(53):55042-55050. http://dx.doi.org/10.1074/jbc.M408881200. PMid:15475354.

Bastian A. \& Schäfer H. 2001. Human alpha-defensin 1 (HNP-1) inhibits adenoviral infection in vitro. Regul. Pept. 101(1-3):157-161. http://dx.doi. org/10.1016/S0167-0115(01)00282-8. PMid:11495691.

Bechinger B. 1999. The structure, dynamics and orientation of antimicrobial peptides in membranes by multidimensional solid-state NMR spectroscopy. Biochim. Biophys. Acta 1462(1/2):157-183. http://dx.doi.org/10.1016/ S0005-2736(99)00205-9. PMid:10590307.

Belaid A., Aouni M., Khelifa R., Trabelsi A., Jemmali M. \& Hani K. 2002. In vitro antiviral activity of dermaseptins against herpes simplex virus type 1. J. Med. Virol. 66(2):229-234. http://dx.doi.org/10.1002/jmv.2134. PMid:11782932.

Bello J., Bello H.R. \& Granados E. 1982. Conformation and addregation of melittin: dependence on $\mathrm{pH}$ and concentration. Biochemistry 21(3):461465. http://dx.doi.org/10.1021/bi00532a007. PMid:7066299.

Benachir T. \& Lafleur M. 1995. Study of vesicle leakage induced by melittin. Biochim. Biophys. Acta 1235(2):452-460. http://dx.doi.org/10.1016/00052736(95)80035-E. PMid:7756355.

Bowdish D.M., Davidson D.J., Lau Y.E., Lee K., Scott M.G. \& Hancock R.E. 2005. Impact of LL-37 on anti-infective immunity. J. Leukoc. Biol. 77 (4):451-459. http://dx.doi.org/10.1189/jlb.0704380. PMid:15569695.

Bowdish D.M., Davidson D.J., Speert D.P. \& Hancock R.E. 2004. The human cationic peptide LL-37 induces activation of the extracellular signal-regulated kinase and p38 kinase pathways in primary human monocytes. J. Immunol. 172(6):3758-3765. http://dx.doi.org/10.4049/jimmunol.172.6.3758. PMid:15004180.

Brasil 2015. Ministério da Saúde. Ministério da Saúde confirma relação entre vírus Zika e microcefalia. Ministério da Saúde, Brasília. Disponível em <http://portalsaude.saude.gov.br/index.php/cidadao/principal/ agencia-saude/21014-ministerio-da-saude-confirma-relacao-entre-viruszika-e-microcefalia> Acesso em 7 mar. 2016.

Brogden K.A., Ackermann M., McCray Junior P.B. \& Tack B.F. 2003. Antimicrobial peptides in animal sand their role in host defences. Int. J. Antimicrob. Agents 22(5):465-478. http://dx.doi.org/10.1016/S0924-8579(03)00180-8. PMid:14602364.

Cardoso J.L.C., França F.O.S., Wen F.H., Malque C.M.S. \& Haddad J.V. 2003. Animais Peçonhentos no Brasil: Biologia Clinica e Terapêutica dos Acidentes. Sarvier/Fapesp, São Paulo. 550 p.

Chang T.L., Vargas Junior J., Delportillo A. \& Klotman M.E. 2005. Dual role of alpha-defensin-1 in anti-HIV-1 innate immunity. J. Clin. Invest. 115(3):765773. http://dx.doi.org/10.1172/JCI21948. PMid:15719067.

Cragg G.M., Newman D.J. \& Snader K.M. 1997. Natural products in drug discovery and development. J. Nat. Prod. 60(1):52-60. http://dx.doi. org/10.1021/np9604893. PMid:9014353.

Cruz-Landim C. \& Abdalla F.C. 2002. Glândulas Exócrinas das Abelhas. Funpec Editora, Ribeirão Preto. 182 p.

Cuthbertson B.J., Shepard E.F., Chapman R.W. \& Gross P.S. 2002. Diversity of the penaeidin antimicrobial peptides in two shrimp species. Immunogenetics 54(6):442-445. http://dx.doi.org/10.1007/s00251-002-0487-z. PMid:12242595.

Daher K.A., Selsted M.E. \& Lehrer R.I. 1986. Direct inactivation of viruses by human granulocyte defensins. J. Virol. 60(3):1068-1074. PMid:3023659.
De Clercq E. 2001. New developments in anti-HIV chemotherapy. Pure Appl. Chem. 73(1):55-66. http://dx.doi.org/10.1351/pac200173010055.

Dempsey C.E. 1990. The actions of melittin on membranes. Biochim. Biophys. Acta 1031(2):143-161.http://dx.doi.org/10.1016/0304-4157(90)90006-X. PMid:2187536.

Dias A., Bouvier D., Crepin T., McCarthy A.A., Hart D.J., Baudin F., Cusack S. \& Ruigrok R.W.H. 2009. The cap-snatching endonuclease of influenza virus polymerase resides in the PA subunit. Nature 458(7240):914-918. http:// dx.doi.org/10.1038/nature07745. PMid:19194459.

Engler A.C., Shukla A., Puranam S., Buss H.G., Jreige N. \& Hammond P.T. 2011. Effects of side group functionality and molecular weight on the activity of synthetic antimicrobial polypeptides. Biomacromolecules 12(5):1666-1674. http://dx.doi.org/10.1021/bm2000583. PMid:21443181.

Faulkner D.J. 2002. Marine natural products. Nat. Prod. Rep. 19(1):1-48. http://dx.doi.org/10.1039/b009029h. PMid:11902436.

Fechter P., Mingay L., Sharps J., Chambers A., Fodor E. \& Brownlee G.G. 2003. Two aromatic residues in the PB2 subunit of influenza A RNA polymerase are crucial for cap binding. J. Biol. Chem. 278(22):20381-20388. http:// dx.doi.org/10.1074/jbc.M300130200. PMid:12646557.

Flores E.F. 2012. Virologia Veterinária. UFSM, Santa Maria. 1008 p.

Fosgerau K. \& Hoffmann T. 2015. Peptide therapeutics: current status and future directions. Drug Discov. Today 20(1):122-128. http://dx.doi. org/10.1016/j.drudis.2014.10.003. PMid:25450771.

Giansanti F., Massucci M.T., Giardi M.F., Nozza F., Pulsinelli E., Nicolini C., Botti D. \& Antonini G. 2005. Antiviral activity of ovotransferrin derived peptides. Biochem. Biophys. Res. Commun. 331(1):69-73. http://dx.doi. org/10.1016/j.bbrc.2005.03.125. PMid:15845359.

Glättli A., Chandrasekhar I. \& van Gunsteren W.F. 2006. A molecular dunamics study of the bee venom melittin in aqueous solution, in methaol, and inserted in phospholipid bilayer. Eur. Biophys. J. 35(3):255-267. http:// dx.doi.org/10.1007/s00249-005-0033-7. PMid:16322979.

Gordon-Grossman M., Gofman Y., Zimmermann H., Frydman V., Shai Y., Ben-Tal N. \& Goldfarb D. 2009. A combined pulse EPR and montecarlo simulation study provides molecular insight on peptide-membrane interactions. J. Phys. Chem. B 113(38):15128. http://dx.doi.org/10.1021/jp909559d.

Gordon-Grossman M., Zimmermann H., Wolf S.G., Shai Y. \& Goldfarb D. 2012. Investigation of model membrane disruption mechanism by melittin using pulse electron paramagnetic resonance spectroscopy and cryogenic transmission electron microscopy. J. Phys. Chem. B 116(1):179-188. http:// dx.doi.org/10.1021/jp207159z. PMid:22091896.

Habermann E. 1972. Bee and wasps venoms. Science 177(4046):314-322. http://dx.doi.org/10.1126/science.177.4046.314. PMid:4113805.

Heukelbach J., Alencar C.H., Kelvin A.A., Oliveira W.K. \& Pamplona de Góes Cavalcanti L. 2016. Zika virus outbreak in Brazil. J. Infect. Dev. Ctries. 10(2):116-120. http://dx.doi.org/10.3855/jidc.8217. PMid:26927450.

Hood J.L., Jallouk A.P., Campbell N., Ratner L. \& Wickline S.A. 2013. Cytolytic nanoparticules atteuate HIV-1 infectivity. Antivir. Ther. 18(1):95-103. http://dx.doi.org/10.3851/IMP2346. PMid:22954649.

Horne W.S., Wiethoff C.M., Cui C., Wilcoxen K.M., Amorin M., Ghadiri M.R. \& Nemerow G.R. 2005. Antiviral cyclic D,L-alpha-peptides: targeting a general biochemical pathway in virus infections. Bioorg. Med. Chem. 13(17):51455153. http://dx.doi.org/10.1016/j.bmc.2005.05.051. PMid:15993611.

Hsu C.H., Chen C., Jou M.L., Lee A.Y., Lin Y.C., Yu Y.P., Huang W.T. \& Wu S.H. 2005. Structural and DNA-binding studies on the bovine antimicrobial peptide, indolicidin: evidence for multiple conformations involved in binding to membranes and DNA. Nucleic Acids Res. 33(13):4053-4064. http://dx.doi.org/10.1093/nar/gki725. PMid:16034027.

Jenssen H., Andersen J., Mantzilas D. \& Gutteberg T. 2004a. A wide range of medium-sized, highly cationic, alpha-helical peptides show antiviral activity 
against herpes simplex virus. Antiviral Res. 64(2):119-126. http://dx.doi. org/10.1016/S0166-3542(04)00166-4. PMid:15498607.

Jenssen H., Andersen J.H., Uhlin-Hansen L., Gutteberg T.J. \& Rekdal Ø. 2004b. Anti-HSV activity of lactoferricin analogues is only partly related to their affinity for heparan sulfate. Antiviral Res. 61(2):101-109. http://dx.doi. org/10.1016/j.antiviral.2003.09.001. PMid:14670583.

Jenssen H., Hamill P. \& Hancock R.E. 2006. Peptide antimicrobial agents. Clin. Microbiol. Rev. 19(3):491-511. http://dx.doi.org/10.1128/CMR.00056-05. PMid:16847082.

Kantor I.N. 2016. Dengue, Zika y Chikungunya. Medicina, Buenos Aires, 76(2):93-97. PMID: 26942903.

Koumanov K., Momchilova A. \& Wolf C. 2003. Bimodal regulatory effect of melittin and phospholipase A2-activating protein on human type II secretory phospholipase A2. Cell Biol. Int. 27(10):871-877. http://dx.doi. org/10.1016/S1065-6995(03)00176-8. PMid:14499668.

Ladokhin A.S. \& White S.H. 2001. 'Detergent-like' permeabilization of anionic lipid vesicles by melittin. Biochim. Biophis. Acta 1514(2):253-260. http:// dx.doi.org/10.1016/S0005-2736(01)00382-0.

Lee M.T., Hung W.C., Chen F.Y. \& Huang H.W. 2008. Mechanism and kinetics of pore formation in membranes by water-soluble amphipathic peptides. Proc. Natl. Acad. Sci. USA 105(13):5087-5092. http://dx.doi.org/10.1073/ pnas.0710625105. PMid:18375755.

Li Q., Zhao Z., Zhou D., Chen Y., Hong W., Cao L., Yang J., Zhang Y., Shi W., Cao Z., Wu Y., Yan H. \& Li W. 2011. Virucidal activity of a scorpion venom peptide variant mucroporin-M1 against measles, SARS-CoV and influenza H5N1 viruses. Peptides 32(7):1518-1525. http://dx.doi.org/10.1016/j. peptides.2011.05.015. PMid:21620914.

Lu N.Y., Yang K., Li J.L., Yuan B. \& Ma Y.Q. 2013. Vesicle deposition and subsequent membrane-melittininteractions on different substrates: a QCM-D experiment. Biochim. Biophys. Acta 1828(8):1918-1925. http:// dx.doi.org/10.1016/j.bbamem.2013.04.013. PMid:23608122.

Ma Q.Q., Shan A.S., Dong N., Gu Y., Sun W.Y., Hu W.N. \& Feng X.J. 2011. Cell selectivity and interaction with model membranes of Val/Arg-rich peptides. J. Pept. Sci. 17(7):520-526. http://dx.doi.org/10.1002/psc.1360. PMid:21425418.

Mårdberg K., Trybala E., Tufaro F. \& Bergström T. 2002. Herpes simplex virus type 1 glycoprotein $\mathrm{C}$ is necessary for efficient infection of chondroitin sulfate-expressing gro2C cells. J. Gen. Virol. 83(Pt 2):291-300. http:// dx.doi.org/10.1099/0022-1317-83-2-291. PMid:11807221.

McCann K.B., Lee A., Wan J., Roginski H. \& Coventry M.J. 2003. The effect of bovine lactoferrin and lactoferricin B on the ability of feline calicivirus (a norovirus surrogate) and poliovirus to infect cell cultures. J. Appl. Microbiol. 95(5):1026-1033. http://dx.doi.org/10.1046/j.1365-2672.2003.02071.x. PMid:14633031.

Mettenleiter T.C. 2002. Brief overview on cellular virus receptors. Virus Res. 82(1/2):3-8. PMid:11885946.

Mollay C., Kreil G. \& Berger H. 1976. Action of phospholipases on the cytoplasmic membrane of Escherichia coli. Stimulation by melittin. Biochim. Biophys. Acta 426(2):317-324. http://dx.doi.org/10.1016/0005-2736(76)903400 . PMid:766838.

Mosmann T. 1983. Rapid colorimetric assay for cellular growth and survival: application to proliferation and cytotoxicity assays. J. Immunol. Methods 65(1/2):55-63. http://dx.doi.org/10.1016/0022-1759(83)90303-4. PMid:6606682.

Oren Z. \& Shai Y. 1998. Mode of action of linear amphipathic alpha-helical antimicrobial peptides. Biopolymers 47(6):451-463. http://dx.doi. org/10.1002/(SICI)1097-0282(1998)47:6<451::AID-BIP4>3.0.CO;2-F. PMid:10333737.

Pietrantoni A., Ammendolia M.G., Tinari A., Siciliano R., Valenti P. \& Superti F. 2006. Bovine lactoferrin peptidic fragments involved in inhibition of
Echovirus 6 in vitro infection. Antiviral Res. 69(2):98-106. http://dx.doi. org/10.1016/j.antiviral.2005.10.006. PMid:16386316.

Raghuraman H. \& Chattopadhyay A. 2007. Melittin: a membrane-active peptide with diverse functions. Biosci. Rep. 27(4-5):189-223. http:// dx.doi.org/10.1007/s10540-006-9030-z. PMid:17139559.

Reed L.J. \& Muench H. 1938. A simple method of estimating fifty percent endpoints. Am. J. Epidemiol. 27(3):493-497. https://doi.org/10.1093/ oxfordjournals.aje.a118408.

Robinson Junior W.E., McDougall B., Tran D. \& Selsted M.E. 1998. Anti-HIV-1 activity of indolicidin, an antimicrobial peptide from neutrophils. J. Leukoc. Biol. 63(1):94-100. http://dx.doi.org/10.1002/jlb.63.1.94. PMid:9469478

Ruigrok R.W.H., Crepin T., Hart D.J. \& Cusack S. 2010. Towards an atomic resolution understanding of the influenza virus replication machinery. Curr. Opin. Struct. Biol. 20(1):104-113. http://dx.doi.org/10.1016/j. sbi.2009.12.007. PMid:20061134.

Saini S.S., Peterson J.W. \& Chopra A.K. 1997. Melittin binds to secretory phospholipase A2 and inhibits its enzymatic activity. Biochem. Biophys. Res. Commun. 238(2):436-442. http://dx.doi.org/10.1006/bbrc.1997.7295. PMid:9299527.

Scott M.G., Davidson D.J., Gold M.R., Bowdish D. \& Hancock R.E. 2002. The human antomicrobial peptide LL-37 is a multifuncional modulator of innate immune responses. J. Immunol. 169(7):3883-3891. http://dx.doi. org/10.4049/jimmunol.169.7.3883. PMid:12244186.

Shieh M.T., Wudunn D., Montgomery R.I., Esko J.D. \& Spear P.G. 1992. Cell surface receptors for herpes simplex virus are heparan sulfate proteoglycans. J. Cell Biol. 116(5):1273-1281. http://dx.doi.org/10.1083/jcb.116.5.1273. PMid:1310996.

Silva Junior A., Kawazoe U., Freitas F.F.T., Gatti M.S.V., Dolder H., Schumacher R.I., Juliano M.A., Silva M.J. \& Leite A. 2002. Avian anticoccidial activity of a novel membrane interactive peptides elected from phage display libraries. Mol. Biochem. Parasitol. 120(1):53-60. http://dx.doi.org/10.1016/S01666851(01)00439-X. PMid:11849705.

Skalickova S., Heger Z., Krejcova L., Pekarik V., Bastl K., Janda J., Kostolansky F., Vareckova E., Zitka O., Adam V. \& Kizek R. 2015. Perspective of use of antiviral peptides against influenza virus. Viruses 7(10):5428-5442. http:// dx.doi.org/10.3390/v7102883. PMid:26492266.

Song Y.M., Park Y., Lim S.S., Yang S.T., Woo E.R., Park I.S., Lee J.S., Kim J.I., Hahm K.S., Kim Y. \& Shin S.Y. 2005. Cell selectivity and mechanism of action of antimicrobial model peptides containing peptoid residues. Biochemistry 44(36):12094-12106. http://dx.doi.org/10.1021/bi050765p. PMid:16142907.

Spillmann D. 2001. Heparan sulfate: anchor for viral intruders? Biochimie 83(8):811-817. http://dx.doi.org/10.1016/S0300-9084(01)01290-1. PMid:11530214.

Strohl W.R. 2000. The role of natural products in a modern drug discovery program. Drug Discov. Today 5(2):39-41. http://dx.doi.org/10.1016/ S1359-6446(99)01443-9. PMid:10652450.

Tamamura H., Ishihara T., Otaka A., Murakami T., Ibuka T., Waki M., Matsumoto A., Yamamoto N. \& Fujii N. 1996. Analysis of the interaction of an anti-HIV peptide, T22 ([Tyr5, 12, Lys7]-polyphemusin II), with gp120 and CD4 by surface plasmon resonance. Biochim. Biophys. Acta 1298(1):37-44. http:// dx.doi.org/10.1016/S0167-4838(96)00113-6. PMid:8948487.

Tamamura H., Murakami T., Masuda M., Otaka A., Takada W., Ibuka T., Nakashima H., Waki M., Matsumoto A., Yamamoto N. \& Fujii N. 1994. Structure-activity relationships of an anti-HIV peptide, T22. Biochem Biophys. Res. Commun. 205(3):1729-1735. http://dx.doi.org/10.1006/ bbrc.1994.2868. PMid:7811258.

Wachinger M., Kleinschmidt A., Winder D., Von Pechmann N., Ludvigsen A., Neumann M., Holle R., Salmons B., Erfle V. \& Brack-Werner R. 1998. Antimicrobial peptides melittin and cecropin inhibit replication of human immunodeficiency virus 1 by suppressing viral gene expression. J. Gen. 
Virol. 79(Pt 4):731-740. http://dx.doi.org/10.1099/0022-1317-79-4-731. PMid:9568968.

WuDunn D. \& Spear P.G. 1989. Initial interaction of herpes simplex virus with cells is binding to heparan sulfate. J. Virol. 63(1):52-58. PMid:2535752.

Yasin B., Pang M., Turner J.S., Cho Y., Dinh N.N., Waring A.J., Lehrer R.I. \& Wagar E.A. 2000. Evaluation of the inactivation of infectious Herpes simplex virus by host-defense peptides. Eur. J. Clin. Microbiol. Infect. Dis. 19(3):187-194. http://dx.doi.org/10.1007/s100960050457. PMid:10795591.

Yasin B., Wang W., Pang M., Cheshenko N., Hong T., Waring A.J., Herold B.C. Wagar E.A. \& Lehrer R.I. 2004. Theta defensins protect cells from infection by herpes simplex virus by inhibiting viral adhesion and entry. J. Virol. 78(10):5147-5156. http://dx.doi.org/10.1128/JVI.78.10.5147-5156.2004. PMid:15113897.

Yuan P.W., Bartlam M., Lou Z.Y., Chen S.D., Zhou J., He X.J., Lv Z.Y., Ge R.W., Li X.M., Deng T., Fodor E., Rao Z. \& Liu Y. 2009. Crystal structure of an avian influenza polymerase PA(n) reveals an endonuclease active site. Nature 458(7240):909-913. http://dx.doi.org/10.1038/nature07720. PMid:19194458.

Zasloff M. 2002. Antimicrobial peptides of multicellular organisms. Nature 415(6870):389-395. http://dx.doi.org/10.1038/415389a. PMid:11807545.

Zhang N.Z., Qi J.X., Feng S.J., Gao F., Liu J., Pan X.C., Chen R., Li Q.R., Chen Z.S., Li X.Y., Xia C. \& Gao G.F. 2011. Crystal structure of swine major histocompatibility complex class I SLA- $1 * 0401$ and identification of 2009 pandemic swineorigin influenza A H1N1 virus cytotoxic t lymphocyte epitope peptides. J. Virol. 85(22):11709-11724. http://dx.doi.org/10.1128/JVI.05040-11. PMid:21900158.

Zhou J., Qi Y., Diao Q., Wu L., Du X., Li Y. \& Sun L. 2013. Cytotoxicity of melittin and apamin in human hepatic L02 and HepG2 cells in vitro. Toxin Rev. 32(4):60-67. https://doi.org/10.3109/15569543.2013.852108. 